\title{
Genetic divergence between populations of feral and domestic forms of a mosquito disease vector assessed by transcriptomics
}

Dana C Price, Dina M Fonseca

Culex pipiens, an invasive mosquito and vector of West Nile virus in the US, has two morphologically indistinguishable forms that differ dramatically in behavior and physiology. $C x$. pipiens form pipiens is primarily a bird-feeding temperate mosquito, while the sub-tropical $C x$. pipiens form molestus thrives in sewers and feeds on mammals.

Because the feral form can diapause during the cold winters but the domestic form cannot, the two $C x$. pipiens forms are allopatric in northern Europe and, although viable, hybrids are rare. $C x$. pipiens form molestus has spread across all inhabited continents and hybrids of the two forms are common in the US. Here we elucidate the genes and gene families with the greatest divergence rates between these phenotypically diverged mosquito populations, and discuss them in light of their potential biological and ecological effects. After generating and assembling novel transcriptome data for each population, we performed pairwise tests for nonsynonymous divergence $(\mathrm{Ka})$ of homologous coding sequences and examined gene ontology terms that were statistically over-represented in those sequences with the greatest divergence rates. We identified genes involved in digestion (serine endopeptidases), innate immunity (fibrinogens and $\alpha$-macroglobulins), hemostasis (D7 salivary proteins), olfaction (odorant binding proteins) and chitin binding (peritrophic matrix proteins). By examining molecular divergence between closely related yet phenotypically divergent forms of the same species, our results provide insights into the identity of rapidly-evolving genes between incipient species. Additionally, we found that families of signal transducers, ATP synthases and transcription regulators remained identical at the amino acid level, thus constituting conserved components of the $C x$. pipiens proteome. We provide a reference with which to gauge the divergence reported in this analysis by performing a comparison of transcriptome sequences from conspecific (yet allopatric) populations of another member of the $C x$. pipiens complex, $C x$. quinquefasciatus. 
3

\section{Genetic Divergence between Populations of Feral and Domestic forms of a Mosquito} Disease Vector assessed by transcriptomics

6

91 - Rutgers University, Department of Entomology, New Brunswick, NJ, USA

10

11 * To whom correspondence should be addressed:

12

13178 Jones Avenue, New Brunswick NJ 08901

14 E-mail: d.price@rutgers.edu

15 E-mail: dinafons@rci.rutgers.edu

16

17

18 


\section{Introduction}

34 Specific life-history traits of arthropod disease vectors can determine the duration and severity

35 of outbreaks by influencing vectorial capacity (NAS 2008). Plasmodium falciparum, the deadliest

36 of human malaria agents, Wuchereria bancrofti, the widespread causative agent of lymphatic

37 filariasis, and both dengue and yellow fever viruses are transmitted by mosquito vectors that live

38 in close association with and feed near-exclusively on humans. Anthropophilic mosquito

39 phenotypes maximize transmission rates and promote high pathogen virulence of these diseases

40 (Dieckmann et al. 2002). In contrast, zoonotic diseases requiring amplification cycles in non-

41 human vertebrate hosts such as West Nile virus or eastern equine encephalitis will only spill over

42 to humans (often to the detriment of the parasite and the human) if a vector with a broader

43 range of hosts becomes involved (Farajollahi et al. 2011; Kilpatrick et al. 2006). Although blood

44 meal analyses have demonstrated strong associations between vector species and suites of

45 vertebrate hosts, the mechanisms underlying host-choice are still broadly unknown and are often

46 ascribed to environmental instead of genetic causes (Chaves et al. 2010).

47 The northern house mosquito, Culex pipiens, is comprised of two morphologically

48 indistinguishable forms (eco/biotypes), Cx. pipiens form pipiens L. and Cx. pipiens form molestus

49 Forskål (herein f. pipiens and f. molestus, respectively). Despite their morphological identity and

50 very close phylogenetic history (Fonseca et al. 2004b), the two forms exhibit notable ecological

51 and behavioral differences that make their identification possible. The feral form, f. pipiens

52 requires a vertebrate bloodmeal for all egg development (anautogeny), enters winter diapause

53 when ambient light levels decrease below a locally pre-established threshold in the fall

54 (heterodynamous), swarms as a prelude to mating (eurygamous), and is primarily ornithophilic.

55 In contrast, f. molestus can forego a bloodmeal for its first gonotrophic cycle (autogeny), adults 
56 remain gonoactive during winter months (homodynamous), which means they are often

57 restricted to subterranean environments with standing water such as subways and sewers

58 (hypogeous) that remain warm. Males of f. molestus will mate in very confined spaces

59 (stenogamous) and females frequently feed on mammals, including humans (references

60 summarized in Fonseca et al. [2004a]); see Gomes et al. (2012) for latest blood meal studies). Cx.

61 pipiens $\mathrm{f}$. molestus is a worldwide invasive species, spread by humans to all continents except

62 Antarctica (Farajollahi et al. 2011) while f. pipiens has remained restricted to Northern Europe.

63 Cx. pipiens populations within the United States are hybrids of the two forms (Fonseca 2004b,

64 Strickman and Fonseca 2012) and are implicated in the maintenance and transmission of

65 epizootic arboviruses such as West Nile Virus (WNV) to humans resulting in illness and

66 occasionally death (Kramer et al. 2008).

67 The two forms of $C x$. pipiens are very closely related, as is evident from their identical

68 morphology and genetic similarity (Fonseca et al. 2004b). This has led to controversy over their

69 taxonomic standing (Harbach et al. 1984; Spielman et al. 2004). However, they are differentiated

70 at hyper-variable loci such as the flanks of microsatellites (Bahnck \& Fonseca 2006) indicating

71 recent separate evolutionary histories. The genetic similarity despite striking differences in

72 ecology, behavior and physiology indicate that f. molestus may have diverged from f. pipiens and

73 evolved its association with humans as recently as 10,000 years ago (Fonseca et al. 2004b). This

74 recent split represents an exceptional opportunity to test whether targets of molecular evolution

75 in Cx. pipiens mosquitoes can be elucidated using two phenotypically diverged populations.

76 Additionally, by framing the results in context of phenotype, the data generated would serve as a

77 first look at the molecular basis for domestication. 
To start testing this hypothesis, we generated and compared de novo whole-

transcriptomes from one representative population each of $C x$. pipiens f. pipiens and f. molestus using the $C x$. quinquefasciatus genome (CpipJ1.3 Johannesburg, South Africa, (Arensburger et al. 2010) as a reference. Cx. quinquefasciatus is a closely related sibling species of $C x$. pipiens (Farajollahi et al. 2011), and is the only available annotated Culex genome assembly. We performed pairwise comparisons of orthologous coding (CDS) nucleotide sequences to identify genes and gene ontologies that show evidence of evolving at accelerated evolutionary rates between $\mathrm{f}$. pipiens and f. molestus by calculating per-gene rates of non-synonymous substitution per non-synonymous site (Ka, or $\mathrm{dN}$ ). Wang et al. (2011) show that commonly used tests for natural selection that normalize Ka by a 'background mutation rate', or Ks (synonymous substitutions per synonymous site) often produce non-uniform results among closely related genomes, yet find that Ka alone remains stable and an adequate gauge for rate of "uncorrected" peptide evolution. This is primarily due to the varying manner in which Ks is calculated in a likelihood framework by different algorithms, and can also be influenced by sequence composition (Parmley \& Hurst 2007; Wang et al. 2011). Additionally, Ka/Ks calculations are often incorrectly elevated among isolated populations and closely related lineages due to segregating polymorphisms (both neutral and slightly deleterious) present at the time of divergence (Kryazhimskiy \& Plotkin 2008; Mugal et al. 2014; Peterson \& Masel 2009). Since there is minimal phylogenetic distance between the two forms we sequenced, synonymous substitutions would be expected to far outnumber those that are non-synonymous. This scenario is particularly susceptible to the aforementioned biases, as even small stochastic variation in synonymous substitution rates coupled with artifacts in Ks calculation can exert disproportionately large influence on the selection signature (Koonin \& Rogozin 2003; Parmley \& 
101 Hurst 2007; Wang et al. 2009). For these reasons, we elected to use Ka as the primary metric for

102 presentation of our data. As the software we selected for our calculations implements the test in

103 a likelihood framework which corrects for multiple substitutions at sites, a process less likely to

104 have occurred in such closely related taxa, we performed primary calculations using also

105 observed substitutions in addition to those derived from the model and discuss congruence

106 between the two approaches. Although our primary objective was to elucidate components of

107 the mosquito genome evolving at accelerated rate, we also report here ontologies enriched in the

108 set of genes devoid of non-synonymous substitutions as they provide candidates for targets of

109 negative or purifying selection and define critical biological processes and cellular components in

110 the Cx. pipiens genome.

111 To contrast the amount of genetic variation uncovered in the comparison of $C x$. pipiens forms

112 with another geographically isolated yet conspecific population, we repeated the analysis with

113 publicly available transcriptome data from two strains of $C x$. quinquefasciatus: a North American

114 strain (Reid et al. 2012) and the Johannesburg reference (Arensburger et al. 2010). We

115 hypothesized that a greater amount of divergence would be witnessed between the two $C X$.

116 pipiens populations, which exhibit qualifiable phenotypic differences characteristic of the

117 taxonomic forms, rather than between conspecific $C x$. quinquefasciatus populations. In addition,

118 we examined whether particular GO terms present in our results may be derived from

119 ambiguous placement of read data from paralogous or multiple-copy genes by testing for their

120 presence within an enriched ontology list derived from genes which share significant DNA

121 similarity with others in the genome. 


\section{Materials and Methods}

124 Because only Cx. pipiens f. molestus or hybrids of the two Cx. pipiens forms occur in the U.S, we

125 obtained egg rafts of f. pipiens from Baden-Württemberg in southwestern Germany. Multiple

126 individual egg rafts were isolated, hatched and DNA was extracted from ca. 10 larvae from each

127 using a Qiagen DNEasy Blood \& Tissue kit (Qiagen, Valencia CA). PCR-based positive species

128 identification of $C x$. pipiens was performed via the acetylcholinesterase-2 assay developed by

129 Smith and Fonseca (2004), and further to f. pipiens using the CQ11 assay of Bahnck and Fonseca

130 (2006). Field populations of pure f. molestus are difficult to obtain since they are strictly

131 subterranean and mostly found by chance (Fonseca DM personal experience). Therefore, egg

132 rafts of f. molestus were obtained from a young colony, initiated from a large subterranean

133 swarm of females detected in a New York, NY residential basement in December 2010. Blooded

134 females that had been biting local residents were allowed to lay egg rafts in the laboratory and

135 henceforth the colony has been maintained without access to blood. Representative specimens

136 of the NYC colony of f. molestus have been genotyped with a panel of 8 microsatellite loci and

137 have a genetic signature that matches that of populations of $\mathrm{f}$. molestus from southwestern

138 Germany, as do other f. molestus specimens obtained from multiple locations around the world

139 (Fonseca et al. 2004b; Micieli et al. 2013; Turell et al. 2014). Once eggs hatched, larvae of both

140 forms were reared in ceramic pans under a 16:8 L:D cycle on a diet of ground rat chow prior to

141 emergence. Four specimen groups were created: thirty $1^{\text {st }} / 2^{\text {nd }}$ instar, eight $3^{\text {rd }} / 4^{\text {th }}$ instar, eight

142 pupae and eight non-blood fed adult (4 male, 4 female) mosquitoes. Each group was placed in a

143 separate plastic $2 \mathrm{ml}$ microcentrifuge tube containing a $5 \mathrm{~mm}$ sterile stainless steel bead and

$144900 \mathrm{ul}$ QIAzol lysis reagent prior to disruption with a TissueLyser II (Qiagen, Valencia CA) for 2

145 minutes at $20 \mathrm{~Hz}$. Total RNA extraction was then carried out on each group using the RNeasy Plus 
146 Universial kit (Qiagen, Valencia CA) per manufacturer protocol and quantified on a Qubit 2.0 147 fluorometer (Life Technologies) using the RNA Broad-range buffer. One ug of RNA from each 148 group was combined and used to prepare an Illumina sequencing library using the TruSeq RNA

149 Sample Prep kit v2 (Illumina, Inc. San Diego, CA) per manufacturer protocol. The $C x$. pipiens f. 150 molestus library was sequenced twice on an Illumina MiSeq (Illumina, Inc), once using a 500-

151 cycle (2x250bp paired-end) MiSeq Reagent Kit v2, and once using 1/3 of a multiplexed 600-cycle 152 (2x300bp paired-end) MiSeq Reagent Kit v3. Culex pipiens f. pipiens was sequenced once using $1531 / 3$ of a multiplexed 600-cycle (2x300bp paired-end) MiSeq Reagent Kit v3. Raw sequence data 154 were quality trimmed using the CLC Genomics Workbench (Limit score cutoff $=0.05$, CLC Bio, 155 Aarhus, DK).

156 To assemble EST sequences for each mosquito taxon (illustrated in Fig. 1), we used the 157 sequenced genome of another recognized member of the Cx. pipiens complex, Culex 158 quinquefasciatus Say (Arensburger et al. 2010) (for current taxonomy see http://wrbu.si.edu) as 159 a reference. We mapped raw read data for each form individually to the Cx. quinquefasciatus 160 genome CDS sequence, extracted from the CpipJ1.3 genome assembly available via VectorBase

161 (http://www.vectobase.org/organisms/Culex-quinquefasciatus, [Megy et al. 2012]) using the 162 CLC Genomics Workbench (CLC Bio, Aarhus, DK) at a nucleotide similarity of 95\% over a 163 required length fraction of $95 \%$ of the read. Reads that had more than one best alignment (i.e 164 potentially paralogous DNA) were ignored. Consensus sequences for each CDS were then 165 generated from the alignment, with conflicts resolved by choosing the base with the highest 166 additive quality score and a minimum coverage of $2 \mathrm{x}$. Areas of $<2 \mathrm{x}$ coverage were filled with Ns 167 from the reference. The f. pipiens and f. molestus CDS sequences were aligned with each other, 168 and sites with Ns in either or both forms were removed. Genewise (Birney et al. 2004) was used 
169 to create in-frame CDS sequences using the homologous peptide sequence of the $C x$.

170 quinquefasciatus as a guide, and any sequences that had stop codons introduced after this

171 process were removed. Codon alignments were created with TranslatorX (Abascal et al. 2010),

172 guided by a peptide alignment of their translations generated via MAFFT v.6.9 (Katoh \& Toh

173 2010). This codon alignment was used to calculate Ka values using the KaKs Calculator v.2

174 (Wang et al. 2010) using both observed non-synonymous subsitutions and those estimated via

175 maximum-likelihood estimation under likelihood model averaging (MA). We retained Ka values

176 for CDS codon alignments greater than $200 \mathrm{bp}$, or for alignments $<200 \mathrm{bp}$ for which $>50 \%$ of the

177 sequence length (as calculated from the $C x$. quinquefasciatus homolog) was recovered in the $\mathrm{f}$.

178 molestus - f. pipiens comparison. As this test compares single haploid gene sequences, and we

179 reduced allelic variation within and among individuals sequenced from the population by

180 generating haploid consensus gene sequences (above), it is likely that our Ka calculations

181 underestimate the true amount of non-synonymous variation within the populations sequenced.

182 Additionally, the alignment stringency (95\%) of the mapping will exclude genes that have

183 diverged significantly between the subject and the reference, however we find it a conservative

184 value with which to avoid false positives generated from gene paralogs. Enrichment tests were

185 performed using Blast2GO (Conesa et al. 2005) with a reference set consisting of 11,930 genes

186 (Table S1) that met the length criteria above (GO Term Filter Value $=.05$, Term Filter Mode $=$

187 FDR, single-tailed test) and a test set composed of the $95^{\text {th }}$ percentile of CDS sequences with

188 highest calculated Ka. Additionally, to discern possible candidates of purifying selection, a test

189 set of genes lacking non-synonymous substitutions from the f. pipiens - f. molestus comparison

190 was created by selecting 4,575 CDS alignments (generated above, Table S1) from our data with 
191 100\% amino acid identity and used in a separate enrichment test coupled with the reference set 192 above.

For the intra-specific $C x$. quinquefasciatus comparison, data generated by Reid et al.

194 (2012) from colonies started from an Alabama, USA population (strain HAmCq1 and HAmCq8)

195 were compared to the CpipJ1.3 reference as above; briefly, reads from NCBI SRA libraries

196 SRR364515 and SRR364516 were combined and mapped to the CpipJ1.3 CDS sequence,

197 consensus sequences were built using the same protocol and parameters as above, and genewise

198 / translatorX were used to construct the codon alignment prior to Ka calculation. From this, we

199 constructed a reference set containing 13,281 genes which met the f. pipiens - f. molestus length

200 cutoff above. As this was a conspecific comparison (assuming minimal evolution), we used only

201 observed substitutions as opposed to those derived via maximum likelihood estimation (MLE)

202 for the $\mathrm{dN}$ calculation.

203 To examine whether particular gene ontologies present in our results may be derived via 204 ambiguous placement of read data from paralogous or multiple-copy genes, we tested for their 205 presence within an enriched ontology list derived from genes that share significant DNA 206 similarity with others in the genome. This was accomplished by blasting the CX. quinquefasciatus 207 CpipJ1.3 CDS sequence data used above into itself via BLASTN (Altschul et al. 1990) with an e208 value cutoff of $1 \times 10^{-5}$ and saving all 'non-self' hits for genes which had a 95\% similarity over a 209 local alignment of 200nt (a value we chose as our average read length after trim was 211nt).

210 This returned 3,687 (Table S11) sequences that were used as a test set in a Blast2G0 enrichment 211 test against a reference consisting of all CDS sequences.

212 In all tests, we retained GO terms with a False Discovery Rate (FDR) corrected (Benjamini $213 \&$ Hochberg 1995) $\mathrm{p}$-value of $\mathrm{p} \leq .05$. Gene names reported are retained from the $C X$. 
214 quinquefasciatus reference used to construct the consensus. Annotations were performed 215 against the NCBI nr database and via InterProScan v.5 (Apweiler et al. 2000). Phylogenetic 216 analysis of the Peritrophin-A domain-containing proteins was performed by extracting the 217 peptide sequence for each chitin-binding domain from the $C x$. quinquefasciatus homolog 218 corresponding to each of our candidate genes based on coordinates returned via InterproScan 219 v.5 prior to alignment with a selection of peritrophic matrix protein (PMP) and cuticular proteins 220 analogous to peritrophin (CPAP) domains of Jasrapuria et al. (2010) extracted in the same

221 manner. Sequences were aligned using T-COFFEE v.10.00.r1613 (Notredame et al. 2000) and 222 tree reconstruction under automatic model selection and 1500 bootstrap replicates was 223 performed using IQTREE v. 0.9.6 (Minh et al. 2013).

\section{Results and Discussion}

226 Transcriptome sequencing and Ka calculation

227 Transcriptome sequencing generated 58.7 million (11.2Gbp) and 24.7 million (5.3Gbp) of short228 read data for f. molestus and f. pipiens, respectively. The f. molestus data mapped to $18.4 \mathrm{Mbp}$ 229 (74\%) of the $25.0 \mathrm{Mbp}$ Cx. quinquefasciatus CDS sequence reference by length $(15,624$ of 19,019

230 transcripts had at least one mapped read), with an average coverage of $71 \mathrm{x}$ and median coverage $231\left(50^{\text {th }}\right.$ percentile) value of $17 \mathrm{x}$. The f. pipiens RNAseq data mapped to $17.2 \mathrm{Mbp}(70 \%)$ of the $C x$. 232 quinquefasciatus reference by length (14,537 transcripts had at least 1 mapped read) with an 233 average coverage of 45.5x and median of $8 \mathrm{x}$ at our alignment stringency (95\% nt similarity over $23495 \%$ of the read length, see Methods). After refinement by length and coverage (see Methods), 235 the short read alignments were used to create 11,930 pairs of putative ortholog consensus 236 sequences (one pair for each of 11,930 genes). Each taxon contributed 14.15 Mbp of sequence 
237 data. After codon alignment, the gene set was ranked by pairwise Ka value calculated via both

238 the maximum-likelihood estimation and by observed count, and the top 5\% ( $\mathrm{n}=597$, Table S1) of

239 genes from each were selected to create two Blast2GO test sets for Enrichment Analysis (Fisher's

240 Exact Test).

242 Enrichment within the fast-evolving genes

243 When reduced to most-specific terms (i.e parent terms removed), the analysis identified the 244 same seven Gene Ontology (GO) terms as enriched for both the observed and log-likelihood test

245 sets (Table 1): serine-type endopeptidase activity (G00004252), proteolysis (G00006508),

246 receptor binding (G00005102), odorant binding (G00005549), extracellular space (G00005615),

247 chitin metabolic process (GO0006030) and chitin binding (G00008061). As both test sets

248 converged on the same terms, we will present all further results and data tables corresponding to

249 output from the observed count analysis.

The Serine-type endopeptidase activity (G0:0004252) ontology comprises a family of

251 enzymes that utilize a nucleophilic serine at the active site to cleave peptide bonds in proteins.

252 These enzymes are widely distributed throughout both pro- and eukaryotes and classified into

25316 superfamilies. Most eukaryotic serine endopeptidases belong to the Chymotrypsin serine

254 protease S1 family, where both chymotrypsin-like and trypsin-like proteases function as

255 digestive enzymes in hydrolyzing proteins to smaller peptides and amino acids for further

256 digestion (Madala et al. 2010; Rawlings \& Barrett 1994). Annotation of the serine

257 endopeptidases within our enriched set (Table S2) shows 45 of the 50 proteins carry a trypsin

258 domain (Pfam PF00089). Mosquito trypsins, secreted by gut epithelium, function in digestion of

259 protein-rich bloodmeals within the female after encapsulation by a peritrophic matrix (Borovsky 
260 2003; Borovsky \& Schlein 1987). In a process currently considered unique to mosquitoes

261 (Diptera: Culicidae), two forms of trypsin are critical for complete bloodmeal digestion (Felix et

262 al. 1991). Within 1 hour following ingestion, early trypsin protein is translated from mRNA

263 stored in the gut epithelium. This early trypsin protein functions to partially digest the

264 bloodmeal, creating smaller peptides that in turn trigger and regulate late trypsin transcription

265 and translation (Borovsky 2003; Noriega et al. 1999). Late trypsins then further digest the

266 bloodmeal to free amino acids sourced for egg development. This feedback mechanism ensures

267 that digestive proteases are produced only in response to blood (as opposed to

268 carbohydrate/sugar) and in quantities commensurate with "pre-assessment" of bloodmeal

269 protein content by early trypsin digestion. In addition to digestion, Valenzuela et al. (2002)

270 found several secreted salivary serine proteases with homology to Manduca prophenoloxidase-

271 activating enzymes that are likely involved in the innate melanotic immune response.

272 The presence of such elevated levels of trypsin variation between populations may indicate that

273 differences in the source of bloodmeal necessitated adaptive changes in digestive enzymes to

274 hydrolyze differentially abundant proteins. Further study will be required to determine whether

275 the proteins highlighted in our analysis represent early and/or late trypsins, as two proteins

276 carried an annotation of late trypsin and only four trypsins have been annotated as early or late

277 to date within the $C x$. quinquefasciatus genome project (via Vectorbase;

278 https://www.vectorbase.org /organisms/culex-quinquefasciatus retrieved Jun 2014). Five

279 proteins in our set were annotated as coagulation factors, however an NCBI Conserved Domain

280 analysis (http://www.ncbi.nlm.nih.gov/Structure/cdd/wrpsb.cgi, results not shown) fails to

281 return evidence for canonical Gla and/or EGF domains within these peptides, indicative of the

282 coagulation factors (Stavrou \& Schmaier 2010). 
284 proteins to smaller peptides and/or amino acids. This gene ontology contained primarily the

285 serine endopeptidase enzymes discussed above, with the addition of several serine protease

286 inhibitors, metallopeptidases and apoptotic caspases (Table S3).

Receptor binding (G0:0005102) protein molecules interact selectively with specific

288

289

290

291

292

293

294

295

296

297

298

299

300

301

302

303

304

305

cellular receptors to initiate changes in cell function. Eighteen such proteins were present in the enriched set, of which all were found to carry a fibrinogen beta and gamma chain Pfam (PF00147, Table S4) annotation. In the invertebrates, including mosquitoes, fibrinogen-related proteins (FREPs) are restricted to the innate immune response, functioning in pathogen recognition and agglutination (Dong \& Dimopoulos 2009; Hanington \& Zhang 2011). Many Anopheles gambiae FREP genes display immune-responsive transcription after being challenged with bacteria, fungi or both rodent and human malaria protozoa (Dong \& Dimopoulos 2009) indicating that they play a pivotal role in mosquito vectorial capacity. This gene family has undergone lineage-specific duplications with relaxed selective constraints, as the An. gambiae genome contains 59 FREP members, with 32 and 87 members currently annotated in the genomes of Ae. aegypti and $C x$. quinquefasciatus, respectively (Arensburger et al. 2010), while the Drosophila melanogaster genome contains twenty (Wang et al. 2005). This likely reflects the diverse pathogen load faced by each particular dipteran species during its life cycle. Further annotation reveals four putative ficolins in our set, a particular oligomeric lectin containing a C-terminal fibrinogen-like domain able to bind $\mathrm{N}$-acetylglucosamine, a chitin monomer, as part of immune response (Krarup et al. 2004). It is likely that the two populations of $C x$. pipiens sequenced here are challenged by different bacterial communities within their respective environments, and experience both varying larval habitat (subterranean sewers and subway systems [form molestus] vs. stagnant, 
306 above-ground pools [form pipiens]) and bloodmeal hosts (with associated food-borne

307 pathogens; see Serine endopeptidases above). The rate of peptide evolution seen in this

308 component of the innate immune system may be a result of adaptation to these ecological

309 stressors.

310 Members of the odorant binding (G0:0005549) ontology compose a large multi-gene

311 family of water-soluble proteins secreted by support cells into sensillum lymph of the female

312 mosquito antennal hairs (Schultze et al. 2013). These proteins bind various odorant molecules,

313 thus triggering chemosensory mechanisms such as host-seeking and oviposition site recognition

314 (Pelosi \& Maĭda 1995). Characterized by a six alpha-helical domain and the disulphide bonds

315 created by six conserved cysteine residues, the mosquito odorant binding proteins (OBPs) have

316 been studied extensively in the available mosquito genomes. Like the fibrinogens, the OBP

317 protein family has been found to be very divergent within the Culicidae, with low sequence

318 identity between interspecific homologs (Vieira \& Rozas 2011) and can be further divided into

319 four subfamilies: (1) Classic OBPs, which conform to the domain characterization above, (2) PlusC

320 and MinusC OBPs, which contain six additional disulfide-bonded cysteine residues or lack two,

321 respectively (Hekmat-Scafe et al. 2002), and (3) Atypical OBPs, which contain two complete

322 Classic OBP domains (e.g "dimer OBPs", (Vieira \& Rozas 2011). In a recent study, Manoharan et

323 al. (2013) expanded the number of known OBPs from the three published mosquito genomes by

324110 members to a total of 289 , while classifying each by subfamily. Ascribing function to

325 peptides based on sequence homology to known OBPs can prove difficult. Leal et al. (2005) note

326 that several gene families with OBP-like domain structure show no evidence of involvement in

327 olfactory or pheromone-mediated responses, and suggests the term "encapsulins" supersede 
328 "odorant-binding proteins" to more accurately describe the common function (ligand

329 encapsulation) performed by the peptide.

330 An additional protein family often included in evolutionary analyses of mosquito OBPs is

331 the D7 salivary protein family, which exhibits domain structure similar to that of the OBPs with

332 the addition of a seventh helix (Kalume et al. 2005). Classified into short (15-20 kDa) and long

333 (30-36kDa) subfamilies, the long-form D7 salivary proteins contain a second OBP-like domain in

334 an N-terminal extension (Calvo et al. 2006; Valenzuela et al. 2002). The singular domain in the

335 short-form and C-terminus of the long-form salivary D7 protein has been shown to bind biogenic

336 amines (serotonin, histamines and norepinephrine) with high affinity, while the N-terminal

337 domain of the long-form protein binds leukotriene inflammatory mediators, thus inhibiting

338 platelet aggregation, vasoconstriction and inflammation (collectively hemostasis) during blood-

339 feeding (Calvo et al. 2006; Calvo et al. 2009a).

340 Our analysis identified sixteen proteins with an odorant binding cellular function (Table

341 S5), of which fourteen carried a Pfam ID of PF01395 (PBP/GOBP Family). Annotation of these

342 proteins via Vectorbase reveals the list is comprised of six D7 salivary peptides, representing

$34360 \%$ of the known D7 proteins in the Cx. quinquefasciatus genome $(\mathrm{n}=10$,

344 https://www.vectorbase.org/organisms/culex-quinquefasciatus) and eight odorant-binding

345 proteins. The $C x$. quinquefasciatus homologs of all OBPs in our set were recently classified by

346 Manoharan et al. (2013), which allowed us to further assign our representatives to subfamily and

347 cluster. Seven of the eight proteins were of the Classic OBP subfamily, i.e containing a singular

348 OBP domain, with four of these being minus-C type and lacking two of the canonical cysteines.

349 These results indicate that the transcriptome of the two representative Cx. pipiens

350 populations sequenced were most divergent within their odorant-binding domain-containing 
351 proteome at the D7 salivary proteins, and predominantly among the minus-C forms of the Classic

352 Odorant-binding protein subfamily. Since the two forms differ in their propensity for taking

353 mammalian (including human) vs. bird bloodmeals (Huang et al. 2008; Osório et al. 2014) the

354 particular OBP subset highlighted here may contribute to the olfactory response to differing host

355 cues. Additionally, the oviposition habitat available to subterranean mosquitoes (i.e sewers)

356 likely presents olfactory cues that differ from those above ground. The concomitant

357 chemosensory response may necessitate evolution of OBP-encoding genes. As all but one OBP in

358 our set were newly described by Manoharan et al. (2013) and were not included in the tissue-

359 specific expression analysis of Leal et al. (2013), it is unknown whether they may be localized to

360 antennae, palps or other somatic tissues. However, the representation of D7 salivary proteins in

361 the enriched set may indicate that the immunosuppressive complement of mosquito saliva has

362 diverged in accordance with local environment. The mosquito sialome has previously been

363 shown to exhibit accelerated evolutionary pressures at the interspecific level; in a comparative

364 analysis of New World (An. darlingi) and Old World (An. gambiae) Anopheline

365 sialotranscriptomes, Calvo et al. (2009b) found that on average, salivary proteins were only $53 \%$

366 identical at the amino acid level as opposed to $86 \%$ identity among housekeeping genes.

367 Components of the extracellular space (G0:0005615) gene ontology exist outside the cell

368 plasma membrane within interstitial fluids. Our test set contained ten such proteins (Table S6),

369 with seven fibrinogens discussed above (and annotated as having extracellular localization)

370 being re-listed here. The remaining three proteins were of the macroglobulin complement family,

371 which carry alpha-2 macroglobulin family N-terminal (Pfam PF07703) and alpha-macroglobulin

372 receptor (Pfam PF07677) domains. Alpha-2 macroglobulins ( $\alpha 2 \mathrm{M})$ are proteinase-binding and

373 inhibiting glycoproteins commonly secreted by hemocytes within insect hemolymph (Sottrup- 
374 Jensen et al. 1989), which have been found recently to play integral roles in complement-like

375 pathways that bind parasite surface targets (Blandin et al. 2008). The full-length protein exposes

376 a "baited" peptide stretch, which when cleaved by proteinases present with septic injury will

377 change protein conformation to an active state that covalently binds the activating proteinase.

378 This conformational change also exposes binding sites with high affinity for both gram-positive

379 and negative bacteria (Blandin et al. 2008; Sottrup-Jensen et al. 1989). The complex is then

380 targeted for phagocytosis. Like the fibrinogens, the presence of these proteins in the most

381 diverged set indicates that the two populations of $C x$. pipiens may experience very different

382 microbiome challenges, consistent with the differences between forms (e.g utilization of sewers)

383 in larval habitat (Harbach et al. 1984). Furthermore, as $\alpha 2 \mathrm{M}$ inhibits the coagulation proteinases

384 thrombin and factor Xa, it serves to inhibit the coagulation cascade and thus may function in

385 blood-feeding hemostasis as well (de Boer et al. 1993).

386 The Chitin metabolic process (G0:0006030) ontology (inclusive of all genes composing the

387 Chitin binding (G0:0008061) ontology, Table S7, S8) is composed of reactions and pathways

388 involving chitin, a linear polysaccharide polymer that consists of linked glucosamine residues

389 and forms the main component of arthropod exoskeleton, tracheae and peritrophic membrane

390 (PM). Seventeen proteins in the test set were annotated with this term; eleven with a Pfam

391 Chitin binding Peritrophin-A domain (PF01607). The additional two peptides were annotated

392 with a chitinase molecular function, each with two Pfam Chitinase class I domains (PF00182).

393 Peritrophins are structural proteins consisting of one to many chitin-binding domains

394 responsible for cross-linking chitin fibrils (Wang \& Granados 2001). The semi-permeable lattice

395 created, known as the peritrophic membrane, surrounds the insect food bolus and separates it

396 from the midgut epithelial cells. This serves to protect the gut (and insect) from physical damage, 
397 pathogens and toxins. There is evidence that the PM plays a central role in binding toxic free

398 heme via the chitin-binding domain (CBD) (Devenport et al. 2006; Pascoa et al. 2002) during

399 bloodmeal digestion, indicating free CBDs on bound peritrophins of the PM serve additional

400 purposes. Pascoa et al. (2002) found an amount of free heme bound to the Aedes aegypti PM

401 equivalent to hydrolysis of $2 \mathrm{ul}$ of a typical $3 \mathrm{ul}$ bloodmeal. To determine whether our peptides

402 were in fact peritrophins associated with a midgut PM, as opposed to non-specific cuticular

403 proteins analogous to peritrophins (CPAPs, see Jasrapuria et al. [2010]) which also exhibit

404 Peritrophin-A domain homologs, we aligned our nine candidate peptide domains to a selection of

405 those from the classification of Jasrapuria et al. (2010) and produced a maximum-likelihood tree

406 which grouped all 21 of our sequences in a Peritrophic Matrix Protein (PMP) clade at a bootstrap

407 support of $99 \%$ (Fig. S1). This indicates our candidates are in fact likely associated with the

408 midgut PM and involved in digestion.

409 Chitinases are integral enzymes in the creation and destruction of the adult mosquito PM.

410 Initially synthesized as a zymogen upon ingestion of a blood meal, it is later activated by removal

411 of a propeptide from the N-terminus (Bhatnagar et al. 2003) and begins to hydrolyze the

412 glycosidic linkages of the PM chitin matrix to chitobiose (a glucosamine dimer) as the blood meal

413 is digested. Like the PM itself, chitinase enzymes are important research targets for pathogen

414 defense. The Plasmodium parasite ookinete expresses a mosquito chitinase ortholog able to

415 accelerate PM degradation and facilitate escape (Langer \& Vinetz 2001) Bhatnagar et al. (2003)

416 were able to utilize the inhibitory effect of the propeptide on its cognate enzyme to block

417 chitinase activity in both Anopheles gambiae and Ae. aegypti, thus suppressing development of

418 human and avian Plasmodium, respectively, in the two mosquito species. Initial blood meal

419 digestion within the female midgut requires transit of trypsins across the PM, and later, diffusion 
420 back to the ectoperitrophic space (Terra \& Ferreira 1981). The peritrophic membrane has

421 important dual-responsibilities in digestion and immunity, two systems we have associated with

422 other enriched GO terms, further implicating this structure as a driving force in the

423 differentiation of the two $C x$. pipiens populations.

424 The insect immune system has been shown to be a common target of positive selection

425 (Bulmer 2010; Roux et al. 2014), and the role it plays in differentiation of these two mosquitoes

426 is further exemplified by examining the gene with the largest calculated Ka in our comparison

427 (Table S1), a homolog of CPIJ006559 representing a peptidoglycan recognition protein (PGRP)

428 containing a N-acetylmuramoyl-L-alanine amidase (Pfam PF01510). This particular PGRP

429 (PGRP-LC) is a transmembrane molecule that, upon binding bacterial peptidoglycan, triggers the

430 immune deficiency (Imd) pathway in Drosophila (Choe et al. 2005). A manual scan of our test set

431 for other immune-related peptides that may bind peptidoglycan and/or carbohydrate yields

432 eight proteins with a carbohydrate binding cellular function (GO:0030246) of which seven are

433 lectins, with 5 annotated as salivary C-type lectins. These likely serve in food-borne pathogen

434 identification (Ribeiro et al. 2004; Valenzuela et al. 2002) however the possibility exists that

435 these proteins function instead as anti-clotting agents as has been reported in snake venom (Koo

436 et al. 2002) and in the phlebotomine sand fly Lutzomyia longipalpis (Charlab et al. 1999).

437 Highly conserved genes

438 An enrichment test using the gene set devoid of non-synonymous substitutions from the $\mathrm{f}$.

439 pipiens - f. molestus comparison retained 19 significantly enriched GO terms (Table 2). These

440 included primarily transcription and translational machinery (Structural constituent of ribosome,

441 rRNA binding, Transcription regulatory region sequence-specific DNA binding), cell signaling

442 components (GTP binding, GTPase mediated signal transduction, postsynaptic membrane, cell 
443 junction, G-protein coupled receptor signaling, outer membrane-bound periplasmic space, MAPK

444 cascade, regulation of ion transmembrane transport) and ATP coupled proton transport (ATP

445 hydrolysis coupled proton transport, ATP synthesis coupled proton transport, proton-

446 transporting V-type ATPase). Of particular interest were the four GO terms for which all

447 members were present in the enriched set only (i.e the GO term constituents contained only

448 synonymous substitutions; Table S13): (1) outer-membrane bound periplasmic space

449 (G00030288) contained glutamate receptors responsible for postsynaptic excitation of insect

450 neuronal and muscle cells (Briley et al. 1981), (2) the MAPK cascade (G00000165) that

451 communicates biotic and abiotic signals from extracellular ligands to the nucleus, initiating a

452 response (e.g division, apoptosis, etc.) from the cell (McKay \& Morrison 2007), (3) proton-

453 transporting V-type ATPases (GO0033180) that are a diverse and highly conserved membrane-

454 spanning enzyme coupling ATP hydrolysis to proton transport (Nelson et al. 2000), and (4) the

455 transcription regulatory region sequence-specific DNA binding ontology (G00000976) that

456 contains several homeobox domains encoding transcription factors which activate and regulate

457 patterns of morphogenesis (Gehring 1992). Several of these pathways have been previously

458 described as highly conserved in eukaryotes (Bejerano et al. 2004; Li et al. 2011), and when

459 taken together define a genetic "core" in Cx. pipiens that confer critical phenotypes and cellular

460 processes refractory to amino acid substitutions and are the strongest candidates for negative or

461 purifying selective pressures.

462

463 Comparison between geographically isolated populations

464 The populations of $C x$. pipiens forms pipiens and molestus mosquitoes sequenced in this study

465 were geographically isolated. To assess how the amount of variation between $C x$. pipiens forms 
466 (defined by number and IDs of enriched GO terms) reported in our analyses compared to

467 conspecific isolated populations, we repeated our analysis using publicly available data from a

468 recently colonized population of $C x$. quinquefasciatus isolated from Alabama, USA (Reid et al.

469 2012) and the CpipJ1.3 Johannesburg reference CDS sequences. Short-read mapping produced

470 alignments covering 17,410 of 19,019 CDS sequences with > 1 read and covered $19.8 \mathrm{Mbp}(79 \%)$

471 of the reference, with average coverage of $133 \mathrm{x}$ and median coverage of $14.7 \mathrm{x}$. After applying the

472 length and 2x coverage cutoff (see Methods), we retained 13,586 CDS codon alignments for

473 analysis with the $95^{\text {th }}$ percentile test set composed of 679 sequences (Table S9). Blast2GO

474 analysis retained only two significant GO terms when reduced to the most-specific set (Table

475 S10). Neither of these terms (both composed of the same seven genes encoding reverse

476 transcriptase enzymes and retrotransposons) are present in our Cx. pipiens comparison,

477 indicating that the f. pipiens - f. molestus populations sampled here maintain a greater degree of

478 evolutionary protein divergence than the isolated yet conspecific Cx. quinquefasciatus

479 populations.

480

481 Assessing effects of paralogy and sequence identity

482 Some of the gene families and protein domains reported in this study are among the most

483 abundant in the mosquito genome. For example, Interproscan5 analysis of the CpipJ1.3

484 transcripts (not shown) uncovers 477 trypsin and 283 peritrophin-A domains. Even though we

485 discarded sequencing reads with multiple top-scoring genome alignments, to ensure our results

486 were not reflective of incorrect short read placement among multiple paralogous genes, we

487 tested the propensity for our reported GO terms to be enriched among those genes that share

488 significant sequence identity to others in the genome. Using all CpipJ1.3 CDS sequences with 
489 BLASTN alignments $\geq 200 \mathrm{bp}$ at $\geq 95 \%$ similarity to another CDS in the genome (Table S11), we 490 derived a test set which contained 41 enriched terms (Table S12). This list contained no GO 491 terms previously reported here, thus we find no evidence that the resultant terms from our $\mathrm{f}$. 492 pipiens - f. molestus comparison originate from gene families with biased sequence identity. 493

494 Conclusions

495 These are the first insights into the genome-wide molecular differentiation of two closely related 496 yet phenotypically divergent populations of an important disease vector, Cx. pipiens. Analysis of 497 over-represented gene ontology terms within the fastest evolving peptides elucidates the 498 biological systems that are targets of local adaptation. Although further analyses with additional 499 representative populations of the two forms are necessary, our results likely hold clues as to the 500 molecular mechanisms responsible for phenotypic divergence between the two taxonomic forms, 501 and subsequently confer Culex pipiens form molestus the ability to exploit human environments. 502 The recurring localizations within our data to gene families functioning in odorant binding,

503 hemostasis, digestion, and innate immunity can all be linked to a differential propensity of these 504 forms to seek a mammalian host, ability to obtain and process a bloodmeal, and to thrive as 505 larvae and adults in subterranean sewers rich with organic wastes and associated bacteria. In 506 addition, we provide candidate loci for future functional in-vivo assays to qualify effects on 507 phenotype. Interestingly, of the seven GO terms reported in this study, five terms (chitin 508 metabolic process, chitin binding, serine-type endopeptidase activity, proteolysis and odorant 509 binding) were enriched along the 'fly' branch (represented by the Drosophila melanogaster 510 genome [Adams et al. 2000]) of the branch-site selection tests conducted by Roux et al. (2014), 511 indicating they may represent a genetic 'core' remaining under selection and responsible for 
512 adaptive evolution within the Diptera. Further sequencing of members of the Culex pipiens

513 complex (Farajollahi et al. 2011) will enable additional tests involving lineage-specific estimates

514 of evolutionary rates (e.g Mensch et al. 2013) and definition of functional classes of genes with

515 significantly elevated selection coefficients as compared to ancestral states in the phylogeny

516 (Serra et al. 2011), as well as defining the role of differential gene expression in the divergence of

517 a global mosquito vector.

518

519 Availability of supporting data

520 The Illumina sequencing libraries for $C x$. pipiens forms pipiens and molestus are available via the

521 NCBI short read archive accessions SRX[PENDING] and SRX[PENDING], respectively. The

522 pairwise codon alignments are available in Supplemental file 1.

\section{Acknowledgements}

525 We are grateful to Linda McCuiston for her unsurpassed expertise in rearing and colonizing the

526 mosquitoes used in our study, to Nicole Wagner at the Rutgers University School of

527 Environmental and Biological Sciences Genome Cooperative for performing our Illumina

528 Sequencing, and to Peter Armbruster for comments on the manuscript.

\section{References}

531 Abascal F, Zardoya R, and Telford MJ. 2010. TranslatorX: multiple alignment of nucleotide 532 sequences guided by amino acid translations. Nucleic Acids Res 38:W7-13.

533 Adams MD, Celniker SE, Holt RA, Evans CA, Gocayne JD, Amanatides PG, Scherer SE, Li PW, Hoskins RA, Galle RF, George RA, Lewis SE, Richards S, Ashburner M, Henderson SN, Sutton GG, Wortman JR, Yandell MD, Zhang Q, Chen LX, Brandon RC, Rogers YH, Blazej RG, Champe M, Pfeiffer BD, Wan KH, Doyle C, Baxter EG, Helt G, Nelson CR, Gabor GL, Abril JF, Agbayani A, An HJ, Andrews-Pfannkoch C, Baldwin D, Ballew RM, Basu A, Baxendale J, 
Bayraktaroglu L, Beasley EM, Beeson KY, Benos PV, Berman BP, Bhandari D, Bolshakov S, Borkova D, Botchan MR, Bouck J, Brokstein P, Brottier P, Burtis KC, Busam DA, Butler H, Cadieu E, Center A, Chandra I, Cherry JM, Cawley S, Dahlke C, Davenport LB, Davies P, de Pablos B, Delcher A, Deng Z, Mays AD, Dew I, Dietz SM, Dodson K, Doup LE, Downes M, Dugan-Rocha S, Dunkov BC, Dunn P, Durbin KJ, Evangelista CC, Ferraz C, Ferriera S, Fleischmann W, Fosler C, Gabrielian AE, Garg NS, Gelbart WM, Glasser K, Glodek A, Gong F, Gorrell JH, Gu Z, Guan P, Harris M, Harris NL, Harvey D, Heiman TJ, Hernandez JR, Houck J, Hostin D, Houston KA, Howland TJ, Wei MH, Ibegwam C, Jalali M, Kalush F, Karpen GH, Ke Z, Kennison JA, Ketchum KA, Kimmel BE, Kodira CD, Kraft C, Kravitz S, Kulp D, Lai Z, Lasko P, Lei Y, Levitsky AA, Li J, Li Z, Liang Y, Lin X, Liu X, Mattei B, McIntosh TC, McLeod MP, McPherson D, Merkulov G, Milshina NV, Mobarry C, Morris J, Moshrefi A, Mount SM, Moy M, Murphy B, Murphy L, Muzny DM, Nelson DL, Nelson DR, Nelson KA, Nixon K, Nusskern DR, Pacleb JM, Palazzolo M, Pittman GS, Pan S, Pollard J, Puri V, Reese MG, Reinert K, Remington K, Saunders RD, Scheeler F, Shen H, Shue BC, Sidén-Kiamos I, Simpson M, Skupski MP, Smith T, Spier E, Spradling AC, Stapleton M, Strong R, Sun E, Svirskas R, Tector C, Turner R, Venter E, Wang AH, Wang X, Wang ZY, Wassarman DA, Weinstock GM, Weissenbach J, Williams SM, WoodageT, Worley KC, Wu D, Yang S, Yao QA, Ye J, Yeh RF, Zaveri JS, Zhan M, Zhang G, Zhao Q, Zheng L, Zheng XH, Zhong FN, Zhong W, Zhou X, Zhu S, Zhu X, Smith HO, Gibbs RA, Myers EW, Rubin GM, and Venter JC. 2000. The genome sequence of Drosophila melanogaster. Science 287:2185-2195.

Altschul SF, Gish W, Miller W, Myers EW, and Lipman DJ. 1990. Basic local alignment search tool. J Mol Biol 215:403-410.

Apweiler R, Attwood TK, Bairoch A, Bateman A, Birney E, Biswas M, Bucher P, Cerutti L, Corpet F, Croning MD, Durbin R, Falquet L, Fleischmann W, Gouzy J, Hermjakob H, Hulo N, Jonassen I, Kahn D, Kanapin A, Karavidopoulou Y, Lopez R, Marx B, Mulder NJ, Oinn TM, Pagni M, Servant F, Sigrist CJ, Zdobnov EM, and Consortium I. 2000. InterPro--an integrated documentation resource for protein families, domains and functional sites. Bioinformatics 16:1145-1150.

Arensburger P, Megy K, Waterhouse RM, Abrudan J, Amedeo P, Antelo B, Bartholomay L, Bidwell S, Caler E, Camara F, Campbell CL, Campbell KS, Casola C, Castro MT, Chandramouliswaran I, Chapman SB, Christley S, Costas J, Eisenstadt E, Feschotte C, Fraser-Liggett C, Guigo R, Haas B, Hammond M, Hansson BS, Hemingway J, Hill SR, Howarth C, Ignell R, Kennedy RC, Kodira CD, Lobo NF, Mao C, Mayhew G, Michel K, Mori A, Liu N, Naveira H, Nene V, Nguyen N, Pearson MD, Pritham EJ, Puiu D, Qi Y, Ranson H, Ribeiro JM, Roberston HM, Severson DW, Shumway M, Stanke M, Strausberg RL, Sun C, Sutton G, Tu ZJ, Tubio JM, Unger MF, Vanlandingham DL, Vilella AJ, White O, White JR, Wondji CS, Wortman J, Zdobnov EM, Birren B, Christensen BM, Collins FH, Cornel A, Dimopoulos G, Hannick LI, Higgs S, Lanzaro GC, Lawson D, Lee NH, Muskavitch MA, Raikhel AS, and Atkinson PW. 2010. Sequencing of Culex quinquefasciatus establishes a platform for mosquito comparative genomics. Science 330:86-88.

Bahnck CM, and Fonseca DM. 2006. Rapid assay to identify the two genetic forms of Culex (Culex) pipiens L. (Diptera: Culicidae) and hybrid populations. Am J Trop Med Hyg 75:251-255.

Bejerano G, Pheasant M, Makunin I, Stephen S, Kent WJ, Mattick JS, and Haussler D. 2004. Ultraconserved elements in the human genome. Science 304:1321-1325. 
Benjamini Y, and Hochberg Y. 1995. Controlling the False Discovery Rate: A Practical and Powerful Approach to Multiple Testing. Journal of the Royal Statistical Society Series B (Methodological) 57:289-300.

Bhatnagar RK, Arora N, Sachidanand S, Shahabuddin M, Keister D, and Chauhan VS. 2003. Synthetic propeptide inhibits mosquito midgut chitinase and blocks sporogonic development of malaria parasite. Biochem Biophys Res Commun 304:783-787.

Blandin SA, Marois E, and Levashina EA. 2008. Antimalarial responses in Anopheles gambiae: from a complement-like protein to a complement-like pathway. Cell Host Microbe 3:364374.

Borovsky D. 2003. Biosynthesis and control of mosquito gut proteases. IUBMB Life 55:435-441.

Borovsky D, and Schlein Y. 1987. Trypsin and chymotrypsin-like enzymes of the sandfly Phlebotomus papatasi infected with Leishmania and their possible role in vector competence. Med Vet Entomol 1:235-242.

Briley PA, Filbin MT, Lunt GG, and Turner PD. 1981. Glutamate receptor binding in insects and mammals. Mol Cell Biochem 39:347-356.

Bulmer MS. 2010. Evolution of Immune Proteins in Insects. In: Encyclopedia of Life Sciences. Chichester: John Wiley \& Sons, Ltd.

Calvo E, Mans BJ, Andersen JF, and Ribeiro JM. 2006. Function and evolution of a mosquito salivary protein family. J Biol Chem 281:1935-1942.

Calvo E, Mans BJ, Ribeiro JM, and Andersen JF. 2009a. Multifunctionality and mechanism of ligand binding in a mosquito antiinflammatory protein. Proc Natl Acad Sci U S A 106:3728-3733.

Calvo E, Pham VM, Marinotti O, Andersen JF, and Ribeiro JM. 2009b. The salivary gland transcriptome of the neotropical malaria vector Anopheles darlingi reveals accelerated evolution of genes relevant to hematophagy. BMC Genomics 10:57.

Charlab R, Valenzuela JG, Rowton ED, and Ribeiro JM. 1999. Toward an understanding of the biochemical and pharmacological complexity of the saliva of a hematophagous sand fly Lutzomyia longipalpis. Proc Natl Acad Sci U S A 96:15155-15160.

Chaves LF, Harrington LC, Keogh CL, Nguyen AM, and Kitron UD. 2010. Blood feeding patterns of mosquitoes: random or structured? Front Zool 7:3.

Choe KM, Lee H, and Anderson KV. 2005. Drosophila peptidoglycan recognition protein LC (PGRP-LC) acts as a signal-transducing innate immune receptor. Proc Natl Acad Sci U S A 102:1122-1126.

Conesa A, Götz S, García-Gómez JM, Terol J, Talón M, and Robles M. 2005. Blast2G0: a universal tool for annotation, visualization and analysis in functional genomics research. Bioinformatics 21:3674-3676.

de Boer JP, Creasey AA, Chang A, Abbink JJ, Roem D, Eerenberg AJ, Hack CE, and Taylor FB. 1993. Alpha-2-macroglobulin functions as an inhibitor of fibrinolytic, clotting, and neutrophilic proteinases in sepsis: studies using a baboon model. Infect Immun 61:5035-5043.

Devenport M, Alvarenga PH, Shao L, Fujioka H, Bianconi ML, Oliveira PL, and Jacobs-Lorena M. 2006. Identification of the Aedes aegypti peritrophic matrix protein AeIMUCI as a hemebinding protein. Biochemistry 45:9540-9549.

Dieckmann U, Metz J, Sabelis M, and Sigmund K. 2002. Adaptive Dynamics of Infectious Diseases: Cambridge: Cambridge University Press.

Dong Y, and Dimopoulos G. 2009. Anopheles fibrinogen-related proteins provide expanded pattern recognition capacity against bacteria and malaria parasites. J Biol Chem 284:98359844. 
628 Farajollahi A, Fonseca DM, Kramer LD, and Marm Kilpatrick A. 2011. "Bird biting" mosquitoes and human disease: a review of the role of Culex pipiens complex mosquitoes in epidemiology. Infect Genet Evol 11:1577-1585.

Felix CR, Betschart B, Billingsley PF, and Freyvogel TA. 1991. Post-feeding induction of trypsin in the midgut of Aedes aegypti L. (Diptera: Culicidae) is separable into two cellular phases. Insect Biochemistry 21:197-203.

Fonseca D, Keyghobadi N, Malcolm C, Mogi M, Schaffner F, Fleischer R, and Wilkerson R. $2004 \mathrm{a}$. Response to Outbreak of West Nile virus in North America. Science 306:1473-1475.

Fonseca DM, Keyghobadi N, Malcolm CA, Mehmet C, Schaffner F, Mogi M, Fleischer RC, and Wilkerson RC. 2004b. Emerging vectors in the Culex pipiens complex. Science 303:15351538.

Gehring WJ. 1992. The homeobox in perspective. Trends Biochem Sci 17:277-280.

Gomes B, Parreira R, Sousa CA, Novo MT, Almeida AP, Donnelly MJ, and Pinto J. 2012. The Culex pipiens complex in continental Portugal: distribution and genetic structure. J Am Mosq Control Assoc 28:75-80.

Hanington PC, and Zhang SM. 2011. The primary role of fibrinogen-related proteins in invertebrates is defense, not coagulation. J Innate Immun 3:17-27.

Harbach R, Harrison B, and Gad A. 1984. Culex (Culex) molestus Forskal (Diptera: Culicidae): neotype designation, description, variation, and taxonomic status. Proc Entomol Soc Wash 86:521-542.

Hekmat-Scafe DS, Scafe CR, McKinney AJ, and Tanouye MA. 2002. Genome-wide analysis of the odorant-binding protein gene family in Drosophila melanogaster. Genome Res 12:13571369.

Huang S, Molaei G, and Andreadis TG. 2008. Genetic insights into the population structure of Culex pipiens (Diptera: Culicidae) in the Northeastern United States by using microsatellite analysis. Am J Trop Med Hyg 79:518-527.

Jasrapuria S, Arakane Y, Osman G, Kramer KJ, Beeman RW, and Muthukrishnan S. 2010. Genes encoding proteins with peritrophin A-type chitin-binding domains in Tribolium castaneum are grouped into three distinct families based on phylogeny, expression and function. Insect Biochem Mol Biol 40:214-227.

Kalume DE, Okulate M, Zhong J, Reddy R, Suresh S, Deshpande N, Kumar N, and Pandey A. 2005. A proteomic analysis of salivary glands of female Anopheles gambiae mosquito. Proteomics 5:3765-3777.

Katoh K, and Toh H. 2010. Parallelization of the MAFFT multiple sequence alignment program. Bioinformatics 26:1899-1900.

Kilpatrick AM, Kramer LD, Jones MJ, Marra PP, and Daszak P. 2006. West Nile virus epidemics in North America are driven by shifts in mosquito feeding behavior. PLoS Biol 4:e82.

Koo BH, Sohn YD, Hwang KC, Jang Y, Kim DS, and Chung KH. 2002. Characterization and cDNA cloning of halyxin, a heterogeneous three-chain anticoagulant protein from the venom of Agkistrodon halys brevicaudus. Toxicon 40:947-957.

Koonin EV, and Rogozin IB. 2003. Getting positive about selection. Genome Biol 4:331. Kramer LD, Styer LM, and Ebel GD. 2008. A global perspective on the epidemiology of West Nile virus. Annu Rev Entomol 53:61-81.

Krarup A, Thiel S, Hansen A, Fujita T, and Jensenius JC. 2004. L-ficolin is a pattern recognition molecule specific for acetyl groups. J Biol Chem 279:47513-47519.

Kryazhimskiy S, and Plotkin JB. 2008. The population genetics of dN/dS. PLoS Genet 4:e1000304. 
Langer RC, and Vinetz JM. 2001. Plasmodium ookinete-secreted chitinase and parasite penetration of the mosquito peritrophic matrix. Trends Parasitol 17:269-272.

Leal WS. 2005. Pheromone Reception. Topics in Current Chemistry 240:1-36.

Leal WS, Choo YM, Xu P, da Silva CS, and Ueira-Vieira C. 2013. Differential expression of olfactory genes in the southern house mosquito and insights into unique odorant receptor gene isoforms. Proc Natl Acad Sci U S A 110:18704-18709.

Li M, Liu J, and Zhang C. 2011. Evolutionary history of the vertebrate mitogen activated protein kinases family. PLoS One 6:e26999.

Madala PK, Tyndall JD, Nall T, and Fairlie DP. 2010. Update 1 of: Proteases universally recognize beta strands in their active sites. Chem Rev 110:PR1-31.

Manoharan M, Ng Fuk Chong M, Vaïtinadapoulé A, Frumence E, Sowdhamini R, and Offmann B. 2013. Comparative genomics of odorant binding proteins in Anopheles gambiae, Aedes aegypti, and Culex quinquefasciatus. Genome Biol Evol 5:163-180.

McKay MM, and Morrison DK. 2007. Integrating signals from RTKs to ERK/MAPK. Oncogene 26:3113-3121.

Megy K, Emrich SJ, Lawson D, Campbell D, Dialynas E, Hughes DS, Koscielny G, Louis C, Maccallum RM, Redmond SN, Sheehan A, Topalis P, Wilson D, and Consortium V. 2012. VectorBase: improvements to a bioinformatics resource for invertebrate vector genomics. Nucleic Acids Res 40:D729-734.

Mensch J, Serra F, Lavagnino NJ, Dopazo H, and Hasson E. 2013. Positive selection in nucleoporins challenges constraints on early expressed genes in Drosophila development. Genome Biol Evol 5:2231-2241.

Micieli MV, Matacchiero AC, Muttis E, Fonseca DM, Aliota MT, and Kramer LD. 2013. Vector competence of Argentine mosquitoes (Diptera: Culicidae) for West Nile virus (Flaviviridae: Flavivirus). J Med Entomol 50:853-862.

Minh BQ, Nguyen MA, and von Haeseler A. 2013. Ultrafast approximation for phylogenetic bootstrap. Mol Biol Evol 30:1188-1195.

Mugal CF, Wolf JB, and Kaj I. 2014. Why time matters: codon evolution and the temporal dynamics of dN/dS. Mol Biol Evol 31:212-231.

Nelson N, Perzov N, Cohen A, Hagai K, Padler V, and Nelson H. 2000. The cellular biology of proton-motive force generation by V-ATPases. J Exp Biol 203:89-95.

Noriega FG, Colonna AE, and Wells MA. 1999. Increase in the size of the amino acid pool is sufficient to activate translation of early trypsin mRNA in Aedes aegypti midgut. Insect Biochem Mol Biol 29:243-247.

Notredame C, Higgins DG, and Heringa J. 2000. T-Coffee: A novel method for fast and accurate multiple sequence alignment. J Mol Biol 302:205-217.

Osório HC, Zé-Zé L, Amaro F, Nunes A, and Alves MJ. 2014. Sympatric occurrence of Culex pipiens (Diptera, Culicidae) biotypes pipiens, molestus and their hybrids in Portugal, Western Europe: feeding patterns and habitat determinants. Med Vet Entomol 28:103-109.

Parmley JL, and Hurst LD. 2007. How common are intragene windows with KA > KS owing to purifying selection on synonymous mutations? J Mol Evol 64:646-655.

Pascoa V, Oliveira PL, Dansa-Petretski M, Silva JR, Alvarenga PH, Jacobs-Lorena M, and Lemos FJ. 2002. Aedes aegypti peritrophic matrix and its interaction with heme during blood digestion. Insect Biochem Mol Biol 32:517-523.

Pelosi P, and Măda R. 1995. [Physiological functions of odorant-binding proteins]. Biofizika 40:137-145. 
Peterson GI, and Masel J. 2009. Quantitative prediction of molecular clock and ka/ks at short timescales. Mol Biol Evol 26:2595-2603.

Rawlings ND, and Barrett AJ. 1994. Families of serine peptidases. Methods Enzymol 244:19-61.

Reid WR, Zhang L, Liu F, and Liu N. 2012. The transcriptome profile of the mosquito Culex quinquefasciatus following permethrin selection. PLoS One 7:e47163.

Ribeiro JM, Charlab R, Pham VM, Garfield M, and Valenzuela JG. 2004. An insight into the salivary transcriptome and proteome of the adult female mosquito Culex pipiens quinquefasciatus. Insect Biochem Mol Biol 34:543-563.

Roux J, Privman E, Moretti S, Daub JT, Robinson-Rechavi M, and Keller L. 2014. Patterns of positive selection in seven ant genomes. Mol Biol Evol 31:1661-1685.

Schultze A, Pregitzer P, Walter MF, Woods DF, Marinotti O, Breer H, and Krieger J. 2013. The coexpression pattern of odorant binding proteins and olfactory receptors identify distinct trichoid sensilla on the antenna of the malaria mosquito Anopheles gambiae. PLoS One 8:e69412.

Serra F, Arbiza L, Dopazo J, and Dopazo H. 2011. Natural selection on functional modules, a genome-wide analysis. PLoS Comput Biol 7:e1001093.

Smith JL, and Fonseca DM. 2004. Rapid assays for identification of members of the Culex (Culex) pipiens complex, their hybrids, and other sibling species (Diptera: culicidae). Am J Trop Med Hyg 70:339-345.

Sottrup-Jensen L, Sand O, Kristensen L, and Fey GH. 1989. The alpha-macroglobulin bait region. Sequence diversity and localization of cleavage sites for proteinases in five mammalian alpha-macroglobulins. J Biol Chem 264:15781-15789.

Spielman A, Andreadis TG, Apperson CS, Cornel AJ, Day JF, Edman JD, Fish D, Harrington LC, Kiszewski AE, Lampman R, Lanzaro GC, Matuschka FR, Munstermann LE, Nasci RS, Norris DE, Novak RJ, Pollack RJ, Reisen WK, Reiter P, Savage HM, Tabachnick WJ, and Wesson DM. 2004. Outbreak of West Nile virus in North America. Science 306:1473-1475; author reply 1473-1475.

Stavrou E, and Schmaier AH. 2010. Factor XII: what does it contribute to our understanding of the physiology and pathophysiology of hemostasis \& thrombosis. Thromb Res 125:210215.

Strickman D and Fonseca DM. 2012. Autogeny in Culex pipiens complex mosquitoes from the San Francisco Bay Area. Am J Trop Med Hyg 87:719-726.

Terra WR, and Ferreira C. 1981. The physiological role of the peritrophic membrane and trehalase: Digestive enzymes in the midgut and excreta of starved larvae of Rhynchosciara. Journal of Insect Physiology 27:325-331.

Turell M, Dohm D, and Fonseca D. 2014. Comparison of the potential for different genetic forms in the Culex pipiens complex (Diptera: Culicidae) in North America to transmit Rift Valley fever virus. Journal of the American Mosquito Control Association In press.

Valenzuela JG, Pham VM, Garfield MK, Francischetti IM, and Ribeiro JM. 2002. Toward a description of the sialome of the adult female mosquito Aedes aegypti. Insect Biochem Mol Biol 32:1101-1122.

Vieira FG, and Rozas J. 2011. Comparative genomics of the odorant-binding and chemosensory protein gene families across the Arthropoda: origin and evolutionary history of the chemosensory system. Genome Biol Evol 3:476-490. 
764 Wang D, Liu F, Wang L, Huang S, and Yu J. 2011. Nonsynonymous substitution rate (Ka) is a relatively consistent parameter for defining fast-evolving and slow-evolving proteincoding genes. Biol Direct 6:13.

Wang D, Zhang S, He F, Zhu J, Hu S, and Yu J. 2009. How do variable substitution rates influence Ka and Ks calculations? Genomics Proteomics Bioinformatics 7:116-127.

Wang D, Zhang Y, Zhang Z, Zhu J, and Yu J. 2010. KaKs_Calculator 2.0: a toolkit incorporating gamma-series methods and sliding window strategies. Genomics Proteomics Bioinformatics 8:77-80.

Wang P, and Granados R. 2001. Molecular structure of the peritrophic membrane (PM): Identification of potential PM target sites for insect control. Archives of Insect Biochemistry and Physiology 47:110-118.

Wang X, Zhao Q, and Christensen BM. 2005. Identification and characterization of the fibrinogenlike domain of fibrinogen-related proteins in the mosquito, Anopheles gambiae, and the fruitfly, Drosophila melanogaster, genomes. BMC Genomics 6:114. 


\section{Figure Legends}

780 Figure 1. Illustration of codon alignment generation process. 1. Illumina short read data are 781 aligned to $C x$. quinquefasciatus reference CDS sequence and used to build consensus sequences 782 for both Cx. pipiens forms pipiens and molestus. 2. Consensus sequences for each gene are 783 aligned, homologous positions free of Ns are removed and spliced. 3. GeneWise is used along 784 with the corresponding full length $C x$. quinq. peptide to create in-frame f. pipiens/f. molestus EST 785 sequences from spliced alignments. 4. Codon alignments are created from EST sequences using 786 TranslatorX. Ns denote unknown and/or unrecovered nucleotide data.

\section{Supporting Information captions}

789 Figure S1. Maximum-likelihood phylogenetic tree showing monophyly of peritrophin-A domains reported here with peritrophic matrix proteins (labeled PMP), exclusive of the cuticular 791 proteins analogous to peritrophins (labeled CPAP) of Jasrapuria et al. (2010). NCBI GI numbers

792 are appended to Tribolium castaneum sequence IDs; all sequences are suffixed with

793 "_subseq_[coordinate of first amino acid extracted]-[length of extracted peptide window]".

794 Table S1. Observed and estimated Ka calculations, annotation and top-scoring Pfam IDs

795 corresponding with 11,931 pairwise Culex pipiens forms pipiens and molestus homologous

796 codon sequence alignments (ordered by decreasing Ka). Columns two and three denote genes

797 present in the 95th percentile as ranked by Ka calculated using observed and likelihood

798 estimated non-synonymous substitutions, respectively.

799 Table S2. Gene set composing the serine-type endopeptidase ontology, found to be enriched in 800 the 95th percentile of top-scoring Culex pipiens forms pipiens and molestus homologous codon 801 sequence alignments as ranked by Ka value.

802 Table S3. Gene set composing the proteolysis ontology, found to be enriched in the 95th 803 percentile of top-scoring Culex pipiens forms pipiens and molestus homologous codon sequence 804 alignments as ranked by Ka value.

805 Table S4. Gene set composing the receptor binding ontology, found to be enriched in the 95th 806 percentile of top-scoring Culex pipiens forms pipiens and molestus homologous codon sequence 807 alignments as ranked by Ka value. 
808 Table S5. Gene set composing the odorant binding ontology, found to be enriched in the 95th 809 percentile of top-scoring Culex pipiens forms pipiens and molestus homologous codon sequence

810 alignments as ranked by Ka value.

811 Table S6. Gene set composing the extracellular space ontology, found to be enriched in the 95th

812 percentile of top-scoring Culex pipiens forms pipiens and molestus homologous codon sequence

813 alignments as ranked by Ka value.

814 Table S7. Gene set composing the chitin binding ontology, found to be enriched in the 95th

815 percentile of top-scoring Culex pipiens forms pipiens and molestus homologous codon sequence

816 alignments as ranked by Ka value.

817 Table S8. Gene set composing the chitin metabolic process ontology, found to be enriched in the

818 95th percentile of top-scoring Culex pipiens forms pipiens and molestus homologous codon

819 sequence alignments as ranked by Ka value.

820 Table S9. Ka calculations corresponding with 13,587 pairwise Culex quinquefasciatus strain

821 HAmCq and CpipJ1.3 homologous codon sequence alignments. Colum two denotes genes present

822 in the 95th percentile as ranked by Ka calculated using observed non-synonymous substitutions.

823 Table S10. Gene ontology terms enriched in the upper 95th percentile of pairwise $\mathrm{dN}$ values

824 calculated using Culex quinquefasciatus strains HAmCq and CpipJ1.3 homologous codon sequence 825 alignments.

826 Table S11. BLASTN output detailing the 3,687 Culex quinquefasciatus CDS sequences with at

827 least one BLASTN alignment $\geq 200 \mathrm{bp}$ at $\geq 95 \%$ similarity to another CDS in the genome.

828 Table S12. Gene ontology terms enriched in the set of 3,687 Culex quinquefasciatus CDS

829 sequences with at least one BLASTN alignment > 200bp at > 95\% homology to another CDS in 830 the genome.

831 Table S13. Extended analysis for all genes belonging to the GO terms from the highly conserved 832 set (Table 2) for which all members were present only in the test set. 


\section{PeerJ Reviewing Manuscript}




\section{Table $\mathbf{1}$ (on next page)}

GO terms enriched in fast-evolving genes.

Gene ontology terms enriched in the upper 95th percentile of pairwise $d N$ values calculated using Culex pipiens forms pipiens and molestus homologous codon sequence alignments. 


\begin{tabular}{|c|c|c|c|c|c|c|c|}
\hline GO ID & Go Term & FDR & $p$ & $\begin{array}{l}\text { \# in test } \\
\text { set }\end{array}$ & $\begin{array}{l}\text { \# in ref. } \\
\text { set }\end{array}$ & $\begin{array}{l}\text { \# unannotated } \\
\text { test set }\end{array}$ & $\begin{array}{l}\text { \# unannotated } \\
\text { reference set }\end{array}$ \\
\hline GO:0004252 & serine-type endopeptidase activity & $1.20 \mathrm{E}-13$ & $7.60 \mathrm{E}-17$ & 51 & 232 & 364 & 7988 \\
\hline GO:0006508 & proteolysis & $1.40 \mathrm{E}-09$ & $1.80 \mathrm{E}-12$ & 71 & 546 & 344 & 7674 \\
\hline GO:0005102 & receptor binding & $7.50 \mathrm{E}-09$ & $1.50 \mathrm{E}-11$ & 25 & 80 & 390 & 8140 \\
\hline GO:0005549 & odorant binding & $1.40 \mathrm{E}-06$ & $3.20 \mathrm{E}-09$ & 16 & 39 & 399 & 8181 \\
\hline GO:0005615 & extracellular space & 7.30E-04 & $2.00 \mathrm{E}-06$ & 10 & 23 & 405 & 8197 \\
\hline GO:0006030 & chitin metabolic process & $5.80 \mathrm{E}-03$ & $1.70 \mathrm{E}-05$ & 17 & 93 & 398 & 8127 \\
\hline $\begin{array}{c}\mathrm{GO}: 0008061 \\
2\end{array}$ & chitin binding & $1.20 \mathrm{E}-02$ & $4.80 \mathrm{E}-05$ & 15 & 81 & 400 & 8139 \\
\hline
\end{tabular}




\section{Table 2 (on next page)}

GO terms enriched in slow-evolving genes.

Gene ontology terms enriched in the set of 4,575 pairwise Culex pipiens forms pipiens and molestus homologous codon alignments devoid of non-synonymous substitutions. Asterisks indicate terms for which all members were present only in the test set. 


\begin{tabular}{|c|c|c|c|c|c|c|c|}
\hline GO ID & Go Term & FDR & $p$ & $\begin{array}{l}\text { \# in test } \\
\text { set }\end{array}$ & $\begin{array}{l}\text { \# in ref. } \\
\text { set }\end{array}$ & $\begin{array}{l}\text { \# unannot. } \\
\text { test set }\end{array}$ & $\begin{array}{l}\text { \# unannot. } \\
\text { reference set }\end{array}$ \\
\hline GO:0003735 & structural constituent of ribosome & $1.00 \mathrm{E}-15$ & $7.60 \mathrm{E}-19$ & 98 & 30 & 3209 & 5298 \\
\hline GO:0005525 & GTP binding & 2.70E-09 & $1.70 \mathrm{E}-11$ & 113 & 67 & 3194 & 5261 \\
\hline GO:0007264 & small GTPase mediated signal transduction & $2.90 \mathrm{E}-04$ & $6.40 \mathrm{E}-06$ & 104 & 89 & 3203 & 5239 \\
\hline GO:0051301 & cell division & $2.50 \mathrm{E}-03$ & $8.60 \mathrm{E}-05$ & 27 & 12 & 3280 & 5316 \\
\hline GO:0007186 & G-protein coupled receptor signaling pathway & 4.10E-03 & $1.50 \mathrm{E}-04$ & 76 & 66 & 3231 & 5262 \\
\hline GO:0003924 & GTPase activity & $6.60 \mathrm{E}-03$ & $2.50 \mathrm{E}-04$ & 54 & 42 & 3253 & 5286 \\
\hline GO:0030288 & $\begin{array}{l}\text { outer membrane-bounded periplasmic } \\
\text { space* }\end{array}$ & 1.10E-02 & 4.60E-04 & 8 & 0 & 3299 & 5328 \\
\hline GO:0030054 & cell junction & $1.30 \mathrm{E}-02$ & $5.70 \mathrm{E}-04$ & 28 & 16 & 3279 & 5312 \\
\hline GO:0004930 & G-protein coupled receptor activity & $1.80 \mathrm{E}-02$ & $8.10 \mathrm{E}-04$ & 45 & 35 & 3262 & 5293 \\
\hline GO:0000165 & MAPK cascade* & $2.50 \mathrm{E}-02$ & $1.20 \mathrm{E}-03$ & 7 & 0 & 3300 & 5328 \\
\hline GO:0006334 & nucleosome assembly & 2.70E-02 & $1.40 \mathrm{E}-03$ & 18 & 8 & 3289 & 5320 \\
\hline GO:0005509 & calcium ion binding & $3.10 \mathrm{E}-02$ & $1.60 \mathrm{E}-03$ & 103 & 110 & 3204 & 5218 \\
\hline GO:0015991 & ATP hydrolysis coupled proton transport & $3.50 \mathrm{E}-02$ & $1.90 \mathrm{E}-03$ & 14 & 5 & 3293 & 5323 \\
\hline GO:0019843 & rRNA binding & $3.50 \mathrm{E}-02$ & $1.90 \mathrm{E}-03$ & 10 & 2 & 3297 & 5326 \\
\hline GO:0015986 & ATP synthesis coupled proton transport & $3.50 \mathrm{E}-02$ & $1.90 \mathrm{E}-03$ & 10 & 2 & 3297 & 5326 \\
\hline GO:0034765 & regulation of ion transmembrane transport & $3.80 \mathrm{E}-02$ & $2.10 \mathrm{E}-03$ & 15 & 6 & 3292 & 5322 \\
\hline GO:0045211 & postsynaptic membrane & 4.50E-02 & 2.70E-03 & 19 & 10 & 3288 & 5318 \\
\hline GO:0033180 & $\begin{array}{l}\text { proton-transporting V-type ATPase, V1 } \\
\text { domain* }\end{array}$ & 5.00E-02 & $3.10 \mathrm{E}-03$ & 6 & 0 & 3301 & 5328 \\
\hline $\begin{array}{c}\mathrm{GO}: 0000976 \\
2\end{array}$ & $\begin{array}{l}\text { transcription regulatory region sequence- } \\
\text { specific DNA binding* }\end{array}$ & $5.00 \mathrm{E}-02$ & $3.10 \mathrm{E}-03$ & 6 & 0 & 3301 & 5328 \\
\hline
\end{tabular}




\section{1}

Illustration of codon alignment generation process

1. Illumina short read data are aligned to $C x$. quinquefasciatus reference CDS sequence and used to build consensus sequences for both $\mathrm{Cx}$. pipiens forms pipiens and molestus. 2 . Consensus sequences for each gene are aligned, homologous positions free of Ns are removed and spliced. 3. GeneWise is used along with the corresponding full length $C x$. quinq. peptide to create in-frame f. pipiens/f. molestus EST sequences from spliced alignments. 4. Codon alignments are created from EST sequences using TranslatorX. Ns denote unknown and/or unrecovered nucleotide data. 


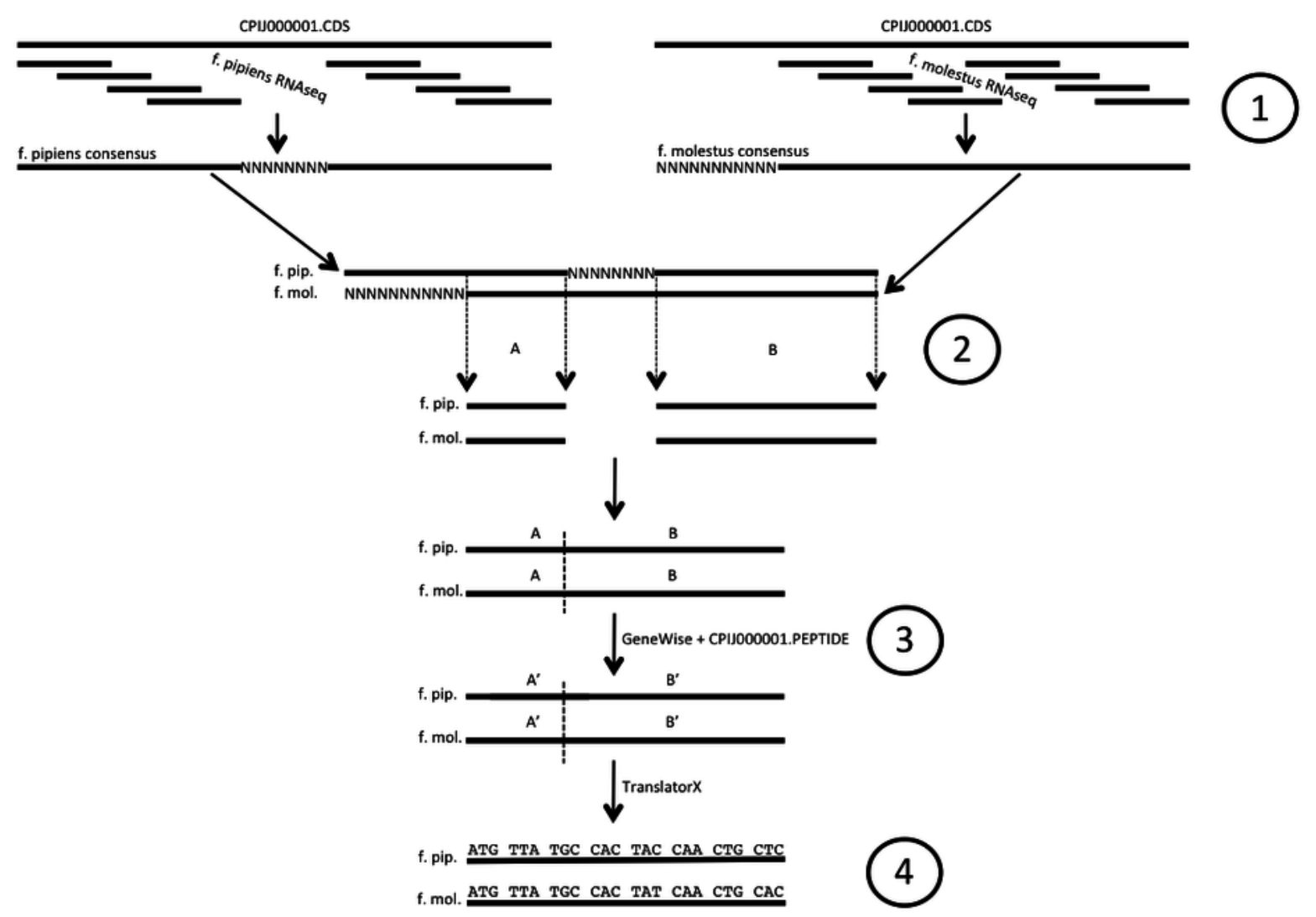

